\title{
Population Genetics and Evolution Analysis Reveal Diversity and Origin of Ammopiptanthus in China.
}

Guai-qiang Chai ( $\nabla$ chaiguaiqiang@126.com )

Yulin University

Yizhong Duan

Yulin University

Peipei Jiao

Tarim University

Zhongyu Du

Ningxia University

Furen Kang

Yulin University

Research article

Keywords: Ammopiptanthus, Population Genetics, Diversity, Evolution

Posted Date: August 9th, 2021

DOI: https://doi.org/10.21203/rs.3.rs-779119/v1

License: (c) (1) This work is licensed under a Creative Commons Attribution 4.0 International License. Read Full License 


\section{Abstract}

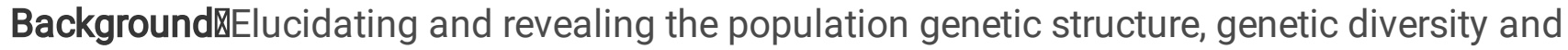
recombination is essential for understanding the evolution and adaptation of species. Ammopiptanthus, which is an endangered survivor from the Tethys in the Tertiary Period, is the only evergreen broadleaf shrub grown in Northwest of China. However, little is known about its genetic diversity and underlying adaptation mechanisms.

Results囚Here, 111 Ammopiptanthus individuals collected from fifteen natural populations in estern China were analyzed by means of the specific locus amplified fragment sequencing (SLAF-seq). Based on the single nucleotide polymorphisms (SNPs) and insertions and deletions (InDels) detected by SLAF-seq, genetic diversity and markers associated with climate and geographical distribution variables were identified. The results of genetic diversity and genetic differentiation revealed that all fifteen populations showed medium genetic diversity, with PIC values ranging from 0.1648 to 0.3081 . AMOVA and Fst indicated that a low genetic differentiation existed among populations. Phylogenetic analysis showed that NX-BG and NMG-DQH of fifteen populations have the highest homology $\llbracket$ while the genetic structure analysis revealed that these Ammopiptanthus germplasm accessions were structured primarily along the basis of their geographic collection, and that an extensive admixture occurred in each group. In addition, the genome-wide linkage disequilibrium (LD) and principal component analysis showed that Ammopiptanthus nanus had a more diverse genomic background, and all genetic populations were clearly distinguished, although different degrees of introgression were detected in these groups.

Conclusion冈Our study could provide guidance to the future design of association studies and the systematic utilization and protection of the genetic variation characterizing the Ammopiptanthus.

\section{Background}

Throughout the world, many plant species are in need of conservation as a result of human activities such as overgrazing and deforestation. Endangered plants that occur in small and isolated populations often need to be managed to mitigate anthropogenic effects such as habitat fragmentation, habitat loss, or climate change[1]. Conservation over the past two decades has increasingly become reliant on genetic data and the insight it provides into the breeding behavior and overall genetic variation within endangered species[2, 3]. Endangered wild species have many characters, such as huge ornamental and medicinal value, stress resistance[4, 5]. Ammopiptanthus is an endangered species from the Tertiary Period, and it is the only evergreen broadleaf shrub grown in Northwest desert of China [6, 7]. The genus Ammopiptanthus (Leguminosae) only comprises of two species, which are $A$. mongolicus(Maxim. ex Kom.) and $A$. nanus(M. Pop.). Both species are diploid with 18 chromosomes and exhibiting a wide range of adaptation $[8,9]$.

In China, Ammopiptanthus are mainly distributed in the northern and western areas, such as Inner Mongolia, Shaanxi, Gansu, Ningxia and Xinjiang, within these areas, Ammopiptanthus is known as a 
drought, cold and heat tolerant shrub[10,11]. However, with the gradual warming of global climate, it remains questionable to what degree the speed of future adaptation can keep up with the pace of climate change. Therefore, a deep understanding of the genetic diversity and genetic regulation of adaptation in Ammopiptanthus is significant. Revealing polymorphisms and genes that determine adaptation would provide the basis for breeding genetically improved germplasms that can be applied in the breeding practice. Breeding resistant cultivars using resistant resources is an economic and effective approach to control this disease. Resistance breeding is also one of the important goals in the desert-plant breeding programme.

As known to all,the genetic diversity and relationships among resistant resources is importance for improving the tolerant varieties. Molecular markers reflect the actual level of genetic variation which exist among genotypes at the DNA level $[12,13]$. Hence, they provide a more accurate estimate with such variation than do either phenotypic or pedigree information. In Ammopiptanthus, the DNA markers such as inter-simple sequence repeat (ISSR), SSR and ESTs have been used for analyzing the germplasm genetic diversity, cultivar fingerprinting and identification of abiotic stress-responsive genes[14-16]. Recently, the rapid development and application of sequence-specific markers such as SSR, EST-SSR, InDels were also reported for sesame [17]. Although various molecular markers are considered to be efficient tools for studying genetic structure, gene flow, mating systems, and estimating genetic variation within a species. Especially, microsatellite markers are used to analyze the effective pollen flow and seed dispersal among the populations and within a species [18, 19]. Unfortunately, a limited number of selected markers used in these studies might provide biased estimates of genetic variability.

However, the limited number of molecular markers are too small to construct a high-density genetic map in most of plant. Fortunately, Specific Length Amplified Fragment sequencing (SLAF-seq) was developed based on high-throughput sequencing technology [20]. This technology allows researchers to design the experimental system through bioinformatics and screen for fragments of a specific length from the constructed SLAF-seq library[21]. The efficiency of SLAF-seq was tested using rice and soybean data[2224], and has been used to construct the highest-density genetic map of common carp[25], without a reference genome sequence. To date, SLAF-seq has been used successfully to construct highdensity genetic maps and study the genomes of many organisms, including wax ground[26], white jute[27], crape myrtle[28], cauliflower[29], Boehmeria nivea[30] and sesame[17]. Moreover, this method has been widely used in GWAS for important traits, as well as in the development of core germplasm[31]. However, the genetic diversity and population structure of Ammopiptanthus are now have not been reported.

In this study, 111 Ammopiptanthus germplasm accessions were selected from the Northwest in China and genotyped using the SLAF-seq method to evaluate their usability as an association-mapping panel. Our objectives were as follows: (a) to assess the genetic diversity as represented by the 111 Ammopiptanthus germplasm accessions; (b) to calculate the characteristics of the population structure; and (c) to estimate the linkage disequilibrium (LD) patterns occurring in the sample of sesame germplasm. Finally, Our results not only develop a valuable resource for further genome-wide association 
studies in Asian Ammopiptanthus and exploiting rich allelic variation for marker-assisted breeding, but also provides guidelines for the conservation, management, and restoration of Ammopiptanthus.

\section{Methods}

\section{Plant varieties and DNA extraction}

A total of 111 Ammopiptanthus samples were evaluated in this study, these individuals were selected from the 1200 core germplasms collected from Northwest of China (Fig. 1). Geographical Coordinates of the collection location ranged from $37^{\circ} \mathrm{N}$ to $41^{\circ} \mathrm{N}$ and from $74^{\circ} \mathrm{E}$ to $106^{\circ} \mathrm{E}$, with an altitude of $1021-2546$ meters. The samples of Ammopiptanthus were stored in a $-80^{\circ} \mathrm{C}$ refrigerator of college of life science, Yulin University, Shaanxi province, China. Genomic DNA was extracted from Ammopiptanthus leaves according to a modified CTAB method [28, 32]. Finally, all samples were sent to Beijing BioMarker Corporation (Beijing, China) for library construction [25, 28]. 
Table 1

Population details of Chinese elms and their climate information.

\begin{tabular}{|c|c|c|c|c|c|c|}
\hline Number & Species & $\begin{array}{l}\text { Population } \\
\text { Location }\end{array}$ & Abbreviation & $\begin{array}{l}\text { Sample } \\
\text { Size }\end{array}$ & $\begin{array}{l}\text { Geographical } \\
\text { Coordinates }\end{array}$ & $\begin{array}{l}\text { Altitude } \\
\text { (m) }\end{array}$ \\
\hline 1 & A.mongolicus & Dongqinghu & NMG-DQH & 6 & $\begin{array}{l}40^{\circ} 30^{\prime} 69^{\prime \prime} \mathrm{N} \\
106^{\circ} 29^{\prime} 91^{\prime \prime} \mathrm{E}\end{array}$ & 1031 \\
\hline \multirow[t]{2}{*}{2} & & Aolunbulage & NMG-ALBLG & 8 & $40^{\circ} 29^{\prime} 59^{\prime \prime} \mathrm{N}$ & 1045 \\
\hline & & & & & $106^{\circ} 16^{\prime} 03^{\prime \prime} E$ & \\
\hline \multirow[t]{2}{*}{3} & & Jilantai & NMG-AZQ & 8 & $40^{\circ} 06^{\prime} 98^{\prime \prime} \mathrm{N}$ & 1072 \\
\hline & & & & & $105^{\circ} 41^{\prime} 99^{\prime \prime E}$ & \\
\hline \multirow[t]{2}{*}{4} & & qianligou & NMG-QLG & 10 & $39^{\circ} 55^{\prime} 07^{\prime \prime} \mathrm{N}$ & 1269 \\
\hline & & & & & $106^{\circ} 53^{\prime} 28^{\prime \prime E}$ & \\
\hline \multirow[t]{2}{*}{5} & & Taositu & NMG- & 9 & $40^{\circ} 10^{\prime} 64^{\prime \prime} \mathrm{N}$ & 1054 \\
\hline & & & & & $106^{\circ} 55^{\prime} 66^{\prime \prime E}$ & \\
\hline \multirow[t]{2}{*}{6} & & Binggou & NX-BG & 3 & $38^{\circ} 30^{\prime} 96^{\prime \prime N}$ & 1125 \\
\hline & & & & & $106^{\circ} 34^{\prime} 66^{\prime \prime E}$ & \\
\hline \multirow[t]{2}{*}{7} & & Biandangou & NX-BDG & 9 & $37^{\circ} 42^{\prime} 65^{\prime \prime} \mathrm{N}$ & 1261 \\
\hline & & & & & $106^{\circ} 19^{\prime} 81^{\prime \prime E}$ & \\
\hline \multirow[t]{2}{*}{8} & & Baijitan & NX-BJT & 10 & $37^{\circ} 54^{\prime} 13^{\prime \prime N}$ & 1303 \\
\hline & & & & & $106^{\circ} 27^{\prime} 65^{\prime \prime E}$ & \\
\hline \multirow[t]{2}{*}{9} & & Hongwei & NX-HW & 6 & $37^{\circ} 26^{\prime} 79^{\prime \prime} \mathrm{N}$ & 1576 \\
\hline & & & & & $104^{\circ} 49^{\prime} 04^{\prime \prime E}$ & \\
\hline \multirow[t]{2}{*}{10} & & Hongshayan & GS-HSY & 11 & $37^{\circ} 30^{\prime} 25^{\prime \prime} \mathrm{N}$ & 1915 \\
\hline & & & & & $103^{\circ} 49^{\prime} 49^{\prime \prime} \mathrm{E}$ & \\
\hline \multirow[t]{2}{*}{11} & A.nanus & Kangsu & $\mathrm{XJ}-\mathrm{KS}$ & 8 & $39^{\circ} 42^{\prime} 12^{\prime \prime} \mathrm{N}$ & 2171 \\
\hline & & & & & $75^{\circ} 03^{\prime} 22^{\prime \prime} \mathrm{E}$ & \\
\hline \multirow[t]{2}{*}{12} & & Bayinkulu & XJ-AHQ & 4 & $39^{\circ} 49^{\prime} 50^{\prime \prime} \mathrm{N}$ & 2157 \\
\hline & & & & & $75^{\circ} 35^{\prime} 25^{\prime \prime} \mathrm{E}$ & \\
\hline \multirow[t]{2}{*}{13} & & Biaoertuokuoyi & $X J-B X$ & 7 & $39^{\circ} 30^{\prime} 28^{\prime \prime} \mathrm{N}$ & 2546 \\
\hline & & & & & $74^{\circ} 52^{\prime} 46^{\prime \prime} \mathrm{E}$ & \\
\hline
\end{tabular}




\begin{tabular}{|c|c|c|c|c|c|c|}
\hline Number & Species & $\begin{array}{l}\text { Population } \\
\text { Location }\end{array}$ & Abbreviation & $\begin{array}{l}\text { Sample } \\
\text { Size }\end{array}$ & $\begin{array}{l}\text { Geographical } \\
\text { Coordinates }\end{array}$ & $\begin{array}{l}\text { Altitude } \\
(\mathrm{m})\end{array}$ \\
\hline \multirow[t]{2}{*}{14} & & Wuheshalu & XJ-WYS & 3 & $39^{\circ} 39^{\prime} 30^{\prime \prime} \mathrm{N}$ & 2250 \\
\hline & & & & & $75^{\circ} 45^{\prime} 18^{\prime \prime} \mathrm{E}$ & \\
\hline \multirow[t]{2}{*}{15} & & Minqin,Gansu & GS-MQ & 9 & $38^{\circ} 59^{\prime} 01^{\prime \prime} \mathrm{N}$ & 1375 \\
\hline & & & & & $102^{\circ} 98^{\prime} 74^{\prime \prime} \mathrm{E}$ & \\
\hline
\end{tabular}

\section{SLAF Sequencing}

Two restriction enzymes Hpy166II and Haell digested the genomic DNA of each Ammopiptanthus individuals, the obtained SLAF tags were used as DNA templates for fragmentation, dual-index paired end adapter ligation, PCR amplification, and target fragment selection[33]. Finally, the SLAF-sequencing was performed on the Illumina HiSeq 2500 system (Illumina, Inc.; San Diego, CA, USA). The information of Ammopiptanthus samples are listed in Table 1.

\section{Evaluation of Data Quality and Identification of SNP Markers}

"Dual-index" software was used to analyze the original data. After removing the adapter sequences, original short reads were evaluated by $\mathrm{GC}$ contents and $\mathrm{Q}_{30}$. All SLAF reads were clustered based on sequence alignments using BLAT software[33]. Polymorphic SLAF tags were determined by comparing sequence variation between different Ammopiptanthus individuals. Meanwhile, SNP markers were identified for polymorphic SLAF tags using GATK and SAMtools[34, 35]. Finally, SNPs that match the criteria were selected for subsequent analysis, and selecting standards of SNPs is according to previous study. [34, 35]

\section{Population Structure and Linkage}

After SNPs pretreatment, the phylogenetic tree was constructed using the MEGA7.0 software. Meanwhile, Bayesian clustering was applied to analyze the population structure of the 111 Ammopiptanthus individuals using software STRUCTURE[36].

Linkage disequilibrium across the genome of Ammopiptanthus was calculated using TASSEL 4.0 software. LD decay for each chromosome was evaluated at a cut-off value of $r_{2}=0.1$. [37, 38]. While the PCA was performed using Online analysis software (smart PCA, part of the EIGENSOFT v6.1).

\section{Results}

SLAF-seq of 111 Ammopiptanthus mongolicus Individuals

After SLAF library construction in 111 Ammopiptanthus mongolicus individuals, a total of $20.92 \mathrm{~Gb}$ of data containing $390.06 \mathrm{Mb}$ reads were obtained, the $\mathrm{GC}$ content is $40.35 \%$ and $\mathrm{Q}_{30}$ is $91.63 \%$. While 957,624 SLAF tags were identified in Ammopiptanthus individuals, with an average coverage of 13.83 per 
samples. SLAF tags were mapped to the reference Ammopiptanthus genome using the BWA software, and 624,223 SLAF tags containing polymorphic SNPs were detected among the 111 Ammopiptanthus individuals (Table 1 and Fig. 2). Of these SLAF tags containing polymorphic SNPs, $44.02 \%(274,782)$ were located on the 18 assembled chromosomes of the Ammopiptanthus reference genome, similar percentage (43.30\%) of the total assembled genome sequence of Ammopiptanthus present in the chromosome assemblies ( $642.5 \mathrm{Mb}$ of $1.535 \mathrm{~Gb}$ ). The number of SLAF tags per chromosome ranged from 5,673 to 17,521 .

Meanwhile, A total of 3,925,962 SNPs were identified among the 111 individuals of Ammopiptanthus, of which 1,261,501 SNPs were identified by both GATK and SAM tools and were subsequently used as SNP markers and the integrity of SNPs in the 111 accessions ranged from 80.66 to $97.66 \%$ (Fig. 3). The raw data for the 111 Ammopiptanthus individuals SLAF-seq have been deposited in the European Nucleotide Archive. The number and distribution of the polymorphic SLAF tags on each chromosome is shown in Supplementary Table 1. Insertion and deletion (INDEL) polymorphisms, are abundant in the genomes of model organisms and are expected to be abundant in Ammopiptanthus as well. We used our computational pipeline to mine 296,977 INDELs from two independent Ammopiptanthus sets, ranging from $1 \mathrm{bp}$ to $831 \mathrm{bp}$ in length. Frameshift INDELs (INDEL length is not multiple of three bases) are under especially strong scrutiny as they generally result in a nonsense mutation and changes in amino acid sequences (Fig. 4A). In our call set we discovered INDELs ranging in size from - 80 to 12 base pairs. The vast majority (95\%) of the INDELs are short, and the distribution is strongly enriched for in-frame INDELs (Fig. 4B).

\section{Genetic diversity and Genetic differentiation of population}

Genetic diversity usually refers to the sum of genetic differentiation and variation among different individuals within a population or among different populations of a species $[39,40]$. Results of genetic diversity showed that the genetic diversity of Ammopiptanthus mongolicus ( $h e=0.32522, h o=0.31129$ ) was higher than that of Ammopiptanthus nanus ( $h e=0.26143$, ho $=0.25834$ ) (Table 2). The population differentiation degree of Ammopiptanthus mongolicus was low $\left(F_{S T}=0.1248\right)$ (Table 3$)$, indicating that the population differentiattion was moderate and the variation mainly existed in the population. While the differentiation degree of Ammopiptanthus nanus population in Xinjiang was high $\left(F_{S T}=0.6989\right)$, indicating that Ammopiptanthus nanus population was highly differentiated and the variation mainly existed between populations. The variation of Ammopiptanthus mongolicus and Ammopiptanthus nanus exists between species, which is closely related to the geographical distance between the two species.

In this study, we also assumed that cpDNA variation was in a drift-migration equilibrium [41], and considerable differentiation of the whole-genome among the Ammopiptanthus populations growing in different geographically remote areas and therefore a high degree of genetic disunity between them are evidenced by the high pairwise genetic distances $\left(F_{S T}\right.$, Table 3$)$, as well as between the Ammopiptanthus mongolicus and Ammopiptanthus nanus groups $\left(F_{S T}=0.5813, P<0.0001\right)$. 
Table 2

Results of genetic diversity of Ammopiptanthus populations.

\begin{tabular}{|lllllll|}
\hline No. & ID & ho & he & NI & WI & PIC \\
\hline 1 & NMG-ALBLG & 0.32475 & 0.32029 & 0.34227 & 0.48802 & 0.25897 \\
\hline 2 & NMG-AZQ & 0.32593 & 0.31756 & 0.33933 & 0.48472 & 0.25705 \\
\hline 3 & NMG-DKTST & 0.27844 & 0.30579 & 0.32419 & 0.47019 & 0.24873 \\
\hline 4 & NMG-DQH & 0.29359 & 0.33438 & 0.36577 & 0.50747 & 0.27043 \\
\hline 5 & NMG-QLG & 0.29790 & 0.30305 & 0.31972 & 0.46526 & 0.24577 \\
\hline 6 & NX-BG & 0.41261 & 0.38689 & 0.46427 & 0.57120 & 0.30764 \\
\hline 7 & NX-BDG & 0.26544 & 0.29864 & 0.31673 & 0.46091 & 0.24319 \\
\hline 8 & NX-BJT & 0.26626 & 0.30448 & 0.32101 & 0.46814 & 0.24755 \\
\hline 9 & NX-HW & 0.38489 & 0.34623 & 0.37864 & 0.52076 & 0.27797 \\
\hline 10 & GS-HSY & 0.26314 & 0.33488 & 0.36654 & 0.50737 & 0.27020 \\
\hline 11 & XJ-KS & 0.13009 & 0.19482 & 0.20904 & 0.33833 & 0.17178 \\
\hline 12 & XJ-AHQ & 0.27917 & 0.27342 & 0.31248 & 0.43996 & 0.23156 \\
\hline 13 & XJ-BX & 0.20823 & 0.18781 & 0.20275 & 0.32706 & 0.16479 \\
\hline 14 & XJ-WYS & 0.44472 & 0.38740 & 0.46489 & 0.57185 & 0.30805 \\
\hline 15 & GS-MQ & 0.229488 & 0.26369 & 0.27965 & 0.42343 & 0.22170 \\
\hline
\end{tabular}


Table 3

The results of nalyses of variance for populations within the entire distributional region and two species of Ammopiptanthus.

\begin{tabular}{|c|c|c|c|c|c|c|}
\hline $\begin{array}{l}\text { Grouping of } \\
\text { species }\end{array}$ & $\begin{array}{l}\text { Source of } \\
\text { variation }\end{array}$ & d.f. & $\begin{array}{l}\text { Sum of } \\
\text { squares }\end{array}$ & $\begin{array}{l}\text { Variation } \\
\text { components }\end{array}$ & $\begin{array}{l}\text { Variation } \\
(\%)\end{array}$ & $\begin{array}{l}\text { Fixation } \\
\text { index }\end{array}$ \\
\hline \multirow[t]{3}{*}{ A.mongolicus } & $\begin{array}{l}\text { Among } \\
\text { populations }\end{array}$ & 10 & 192917.72 & 898.12 & 12.48 & $\begin{array}{l}\mathrm{F}_{\mathrm{ST}}= \\
0.1248\end{array}$ \\
\hline & $\begin{array}{l}\text { Among } \\
\text { individuals } \\
\text { within } \\
\text { populations }\end{array}$ & 69 & 437522.73 & 44.71 & 0.62 & \\
\hline & $\begin{array}{l}\text { Within } \\
\text { individuals }\end{array}$ & 80 & 500118.50 & 6251.48 & 86.89 & \\
\hline \multirow[t]{3}{*}{ A.nanus } & $\begin{array}{l}\text { Among } \\
\text { populations }\end{array}$ & 4 & 115986.48 & 2322.59 & 69.88 & $\begin{array}{l}\mathrm{F}_{\mathrm{ST}}= \\
0.6989\end{array}$ \\
\hline & $\begin{array}{l}\text { Among } \\
\text { individuals } \\
\text { within } \\
\text { populations }\end{array}$ & 26 & 31213.04 & 199.64 & 6.01 & \\
\hline & $\begin{array}{l}\text { Within } \\
\text { individuals }\end{array}$ & 31 & 24838.00 & 801.23 & 24.11 & \\
\hline \multirow[t]{3}{*}{$\begin{array}{l}\text { Total(A.mongolicus } \\
\text { and A.nanus) }\end{array}$} & Among species & 15 & 264033.63 & 1211.33 & 58.13 & $\begin{array}{l}\mathrm{F}_{\mathrm{ST}}= \\
0.5813\end{array}$ \\
\hline & $\begin{array}{l}\text { Among } \\
\text { populations } \\
\text { within species }\end{array}$ & 95 & 86721.02 & 40.35 & 1.94 & $\begin{array}{l}F_{S C}= \\
0.0463\end{array}$ \\
\hline & $\begin{array}{l}\text { Within } \\
\text { populations }\end{array}$ & 111 & 92368.00 & 832.14 & 39.93 & $\begin{array}{l}\mathrm{F}_{\mathrm{CT}}= \\
0.6007\end{array}$ \\
\hline
\end{tabular}

Note: d.f, degrees of freedom; $F_{S T}$, correlation within populations relative to the total; $F_{S C}$, correlation of haplotypes within groups relative to the total; $\mathrm{F}_{\mathrm{CT}}$, correlation within populations relative to groups.

\section{Phylogenetic Relationships Based on SNP Data}

Phylogenetic trees could reflect the evolutionary relationships of different individuals and groups, and which close relatives tend to gather together. So, In order to ascertain the divergence of 111 of Ammopiptanthus species during evolution, we performed the phylogenetic analysis, the results showed all species are clustered into five distinct branches (Fig. 5), and that the majority of individuals can gather in the same group. The GS-MQ population is transplanting species out of five population (GS-MQ, GSHSY, NX-HW, NX-BG and NMG-DQH population). The Ammopiptanthus nanus from Xinjiang province gathered together, while Ammopiptanthus nanus from Gansu province can not gather to a family group. 
Meanwhile, all Ammopiptanthus mongolicus gather to a big family group. The Ammopiptanthus mongolicus GS-HSY and NX-HW are clustered on a large branch, while the remaining communities in Ningxia gather on another branch. The majority of Ammopiptanthus mongolicus gathered together (Fig. 5). Finally, all results indicated that NX-BG and NMG-DQH have the highest homology.

\section{Population Structure and Linkage Disequilibrium Analysis}

To ascertain the divergence of the NMG-DQH, NMG-ALBLG, NMG-AZQ, NMG-QLG, NMG-DKTST, NX-BG, NX-BDG, NX-BJT, NX-HW, GS-HSY, XJ-KS, XJ-AHQ, XJ -BX, XJ-WYS and GS-MQ groups during evolution, principal component, population structure analyses were performed. Additionally, the sequence diversity of the FD, SD and ND germplasms was evaluated. All of the analyses indicated that there are strong divergence between the different Ammopiptanthus groups.

A population structure analysis using the Admixture program and SNP data revealed that 111 Ammopiptanthus germplasms were mainly divided into three groups according to the cross-validation error rate (Fig. 6). Of the three groups, group 1 comprised the most germplasms with 51 followed by group 2 (41 germplasms) and group 3 (19 germplasms). The Ammopiptanthus germplasms distributed in three groups, suggesting these Ammopiptanthus species were genetically diverse.

Meanwhile, Linkage disequilibrium (LD) analysis of these fifteen groups revealed that the distance of LD decay in the NX-HW and XJ-WHS group is longer than that in the other groups (Fig. 7). The results indicated that Ammopiptanthus nanus had a more diverse genomic background.

\section{The principal component analysis}

In order to ascertain the divergence of fifteen population of Ammopiptanthus species during evolution, we performed the principal component analysis. The first three components explained $30.14 \%$ of the total genetic variation, of which the first two components contributed $64.67 \%$ (PC1) and 5.55\% (PC2), The results showed that the NMG-DQH, NMG-ALBLG, NMG-AZQ, NMG-QLG, NMG-DKTST, NX-BG, NX-BDG, NXBJT, NX-HW, GS-HSY, XJ-KS, XJ-AHQ, XJ -BX, XJ-WYS and GS-MQ collections were clearly distinguished (Fig. 8), although existing some degrees of introgression in these groups. All results indicated that a strong divergence between different Ammopiptanthus groups.

\section{Discussion}

High-density genetic maps play an essential role in facilitating discovery of functional genes and comparative analysis of genome structure[42]. However, most current genetic maps contain only about hundreds of markers, due to discovery technologies and genotyping costs [43,44]. Advances in genome sequencing technologies have paved the way for significant improvements in the rapid detection of genetic variation as well as the throughput and wealth of the information obtained. To date, a number of reduced representation sequencing methods have been developed, such as genotyping by sequencing (GBS), type IIB restriction site associated DNA (2b-RAD) [45], and SLAF-sEq. We chose the latter for this 
study because of its advantages, such as lower sequencing costs, higher genotyping accuracy, and efficient detection system.

Genetic diversity is the amount of variation observed between DNA sequences from distinct individuals of a given species[46]. This pivotal concept of population genetics has implications for species health, domestication, management and conservation. As Known to all, population diversity and structure is of fundamental importance for crop breeding programs. Normal passport (geography and/or pedigree) and phenotype data, traditionally used for the assessment of genetic architecture of the population, has been recently paralleled by the use of molecular markers. This is because the molecular markers allowed researchers to distinguish closely related samples and give more precise variation information among genotypes. SLAF-seq methods are currently used in a wide range of applications. These applications mainly include constructing high-density linkage maps[20,47], identifying candidate genes and mutant $[48,49]$, drafting the genome[50] and constructing the core set for rare species[51]. However, the application of population genetics in endangered plant Ammopiptanthus has not been reported. In this study, a high quality of $111,735,304$ 80-bp long paired-end reads, 467,735 SLAFs and 1,261,501 SNPs were generated using high-throughput SLAF-sEq. Then we analyzed the genetic diversity (both morphology and molecular)and population structure of 111 kinds of Ammopiptanthus that grow in different locations of China in order to begin to lay a foundation for future yield-improvement endangered plant breeding programs.

Species that are considered threatened or endangered often exhibit low genetic diversity, especially when populations are small or disconnected[52]. Higher levels of genetic diversity allow species to adapt to environmental changes and reduces their susceptibility to catastrophic extinction events[53]. In this study, the 111 Ammopiptanthus lines were used as materials, by comparing the genetic diversity of Ammopiptanthus mongolicus and Ammopiptanthus nanus, most groups can be divided into the independent group, may be experienced the founder effect or the result of the bottleneck effect, GS-MQ group as compared to other Ammopiptanthus nanus on the related closer to the Ammopiptanthus mongolicus group, showing the geographical position close group is affected by the same climate, tending to be more consistent in evolutionary history.

The species evolution is largely related to the genetic diversity. Generally, species with high genetic diversity are better able to adapt to changing ecological environment, while species with low genetic diversity are less adaptable to the environment and are passive in the permanent evolution. In this study, the genetic diversity and genetic structure of different geographic populations in Ammopiptanthus mongolicus and Ammopiptanthus nanus was explored by SLAF for the first time. Previous studies have shown that the heterozygosity is an important measure of overall genetic diversity. Our results showed that the genetic diversity of Ammopiptanthus mongolicus ( $h e=0.32522, h o=0.31129$ ) was higher than that of Ammopiptanthus nanus ( $h e=0.26143, h o=0.25834$ ). The population differentiation degree of Ammopiptanthus mongolicus was low $\left(F_{S T}=0.1248\right)$, indicating that the population differentiattion was moderate and the variation mainly existed in the population. While the differentiation degree of Ammopiptanthus nanus population in Xinjiang was high $\left(F_{S T}=0.6989\right)$, indicating that Ammopiptanthus 
nanus population was highly differentiated and the variation mainly existed between populations. The variation of Ammopiptanthus mongolicus and Ammopiptanthus nanus exists between species, which is closely related to the geographical distance between the two species.

Gene flow are integral to interpretation of microevolutionary patterns and geographic structure. Through gene flow, we strive to gain insights into evelutionary independence and potential for population diversification, differentiation and ultimately speciation. Gene flow can halt or reduce genetic divergence that accumulates due to population isolation. In this study, the gene flow value (Nm) among Ammopiptanthus mongolicus population was 3.506, it indicates that genetic differentiation between Ammopiptanthus mongolicus populations was small, while the gene flow value (Nm) among Ammopiptanthus nanus population was 0.431, its genetic differentiation is higher than Ammopiptanthus mongolicus. Overall, the average of gene flow $(\mathrm{Nm})$ was 0.360 , indicating that the gene flow level of the whole population was low and the genetic differentiation was high. The main reason may be related to geographical distribution and interspecific isolation. Our analysis results are consistent with the previous studies.

Recently, Ding[54] found that the mountain and monsoon are mainly reasons of terrestrial biodiversity, and by the early to middle Miocene, accelerated diversification and colonization of adjacent regions were likely driven jointly by mountain building and intensification of the monsoon. Similarly, based on our research, we speculate on a possible migration model for Ammopiptanthus species in China. The possible migration route may be from Xinjiang to Gansu, then to Ningxia and Inner Mongolia. It is why we can find some Ammopiptanthus nanus species in Mingqin county of Gansu province. In addition, introduction and cultivation are also the reasons of terrestrial biodiversity, this accuracy of this model needs to be verified in future experiments.

In summary, a SLAF-seq approach for Ammopiptanthus was developed to reveal the genetic diversity, genetic structure and relationship between Ammopiptanthus mongolicus and Ammopiptanthus nanus. Meanwhile, SNP including hundreds of genes between Ammopiptanthus mongolicus and Ammopiptanthus nanus were identifed further. Consequently, our study not only provides a cost-effective approach for Ammopiptanthus genome-wide screening, but also contribute to understanding the diversity and origin of Ammopiptanthus in future research.

\section{Conclusions}

The aim of this study was to reveal the genetic diversity and underlying adaptation mechanisms in Ammopiptanthus. Overall, our results indicated that all fifteen populations showing medium genetic diversity, with PIC values ranging from 0.1648 to 0.3081 . AMOVA and Fst indicated that a low genetic differentiation existed among populations. Phylogenetic analysis showed that NX-BG and NMG-DQH of fifteen populations have the highest homology, while the genetic structure analysis revealed that these Ammopiptanthus germplasm accessions were structured primarily along the basis of their geographic collection, and that an extensive admixture occurred in each group. In addition, the genome-wide linkage 
disequilibrium (LD) and principal component analysis showed that Ammopiptanthus nanus had a more diverse genomic background, and all genetic populations were clearly distinguished, although different degrees of introgression were detected in these groups.

\section{Declarations}

\section{Authors' contributions}

YD designed the study. GC, YD, PJ, ZD, FK, JS and YH performed experiments. GC and YD analyzed the SLAF-seq data and drafted the manuscript. GC, YD and ZD revised the manuscript. All authors contributed to the article and approved the submitted version.

\section{Funding}

This work was supported by the National Natural Science Foundation of China (41601059), Joint Foundation of Huazhong Agricultural University \& Tarim University research cooperation(TDHNLH201701), the Research Foundation of Forestry Industry Development Center in Yulin (2018HX69 and 2020HX01), the PhD research startup fund of Yulin University (18GK11) and Scientific Research Program Funded by Shaanxi Provincial Education Department(21JS042).

\section{Availability of data and materials}

All the data pertaining to the present study has been included in table and/or figure form in the present manuscript and authors are pleased to share analyzed/raw data and plant materials upon reasonable request.

\section{Ethics approval and consent to participate}

Not applicable.

\section{Consent for publication}

Not applicable.

\section{Competing interests}

The authors declare absence of competing interests.

Conflict of Interest Statement: The authors declare that the research was conducted in the absence of any commercial or financial relationships that could be construed as a potential conflict of interest.

\section{References}


1. Vellend M, Baeten L, Becker-Scarpitta A, Boucher-Lalonde V, McCune JL, Messier J, Myers-Smith IH, Sax DF. Plant Biodiversity Change Across Scales During the Anthropocene. Annu Rev Plant Biol. 2017;68:563-86.

2. Tilman D, Clark M, Williams DR, Kimmel K, Polasky S, Packer C. Future threats to biodiversity and pathways to their prevention. Nature. 2017;546(7656):73-81.

3. Wilkening J, Pearson-Prestera W, Mungi NA, Bhattacharyya S. Endangered species management and climate change: When habitat conservation becomes a moving target. Wildl Soc Bull. 2019;43(1):11-20.

4. Engelmann F. Use of biotechnologies for the conservation of plant biodiversity. In Vitro Cellular Developmental Biology Plant. 2011;47(1):5-16.

5. Su Z, Pan B, Zhang M, Shi W. Conservation genetics and geographic patterns of genetic variation of endangered shrub Ammopiptanthus (Fabaceae) in northwestern China. Conserv Genet. 2016;17(2):485-96.

6. Wu Y, Wei W, Pang X, Wang X, Zhang H, Dong B, Xing Y, Li X, Wang M. Comparative transcriptome profiling of a desert evergreen shrub, Ammopiptanthus mongolicus, in response to drought and cold stresses. BMC Genomics. 2014;15(1):671.

7. Liu Y, Zhang L, Meng S, Liu Y, Zhao X, Pang C, Zhang H, Xu T, He Y, Qi M, et al. Expression of galactinol synthase from Ammopiptanthus nanus in tomato improves tolerance to cold stress. $\mathrm{J}$ Exp Bot. 2020;71(1):435-49.

8. Gao F, Wang X, Li X, Xu M, Li H, Abla M, Sun H, Wei S, Feng J, Zhou Y. Long-read sequencing and de novo genome assembly of Ammopiptanthus nanus, a desert shrub. Gigascience. 2018;7(7):1-5.

9. Chen Y, Cao C, Guo Z, Zhang Q, Li S, Zhang X, Gong J, Shen Y. Herbivore exposure alters ion fluxes and improves salt tolerance in a desert shrub. Plant Cell Environ. 2020;43(2):400-19.

10. Ren $M$, Wang Z, Xue $M$, Wang X, Zhang F, Zhang Y, Zhang W, Wang M. Constitutive expression of an A-5 subgroup member in the DREB transcription factor subfamily from Ammopiptanthus mongolicus enhanced abiotic stress tolerance and anthocyanin accumulation in transgenic Arabidopsis. PloS one 2019, 14(10).

11. Pang X, Xue M, Ren M, Nan D, Wu Y, Guo H. Ammopiptanthus mongolicus stress-responsive NAC gene enhances the tolerance of transgenic Arabidopsis thaliana to drought and cold stresses. Genetics molecular biology. 2019;42(3):624-34.

12. Jin M, Guo MY, Han L, Li JL, Yang SY, Su YH. Transcriptome analysis of potential simple sequence repeat markers in Ammopiptanthus mongolicus. Genet Mol Res. 2016;15(3):1-8.

13. Liu M, Shi J, Lu C. Identification of stress-responsive genes in Ammopiptanthus mongolicus using ESTs generated from cold- and drought-stressed seedlings. BMC Plant Biol. 2013;13:88-101.

14. Ge XJ, Yu Y, Yuan YM, Huang HW, Yan C. Genetic diversity and geographic differentiation in endangered Ammopiptanthus (Leguminosae) populations in desert regions of northwest China as revealed by ISSR analysis. Ann Bot. 2005;95(5):843-51. 
15. Liu M, Shi J, Lu C. Identification of stress-responsive genes in Ammopiptanthus mongolicus using ESTs generated from cold- and drought-stressed seedlings. BMC Plant Biol. 2013;13:88.

16. Zhou Y, Gao F, Liu R, Feng J, Li H. De novo sequencing and analysis of root transcriptome using 454 pyrosequencing to discover putative genes associated with drought tolerance in Ammopiptanthus mongolicus. BMC Genom. 2012;13:266.

17. Du H, Zhang H, Wei L, Li C, Duan Y, Wang H. A high-density genetic map constructed using specific length amplified fragment (SLAF) sequencing and QTL mapping of seed-related traits in sesame (Sesamum indicum L.). BMC Plant Biol. 2019;19(1):588.

18. Katsuhara KR, Nakahama N, Komura T, Kato M, Miyazaki Y, Isagi Y, Ito M, Ushimaru A. Development of microsatellite markers for the annual andromonoecious herb Commelina communis $\mathrm{f}$. ciliata (Commelinaceae). Genes Genet Syst. 2019;94(3):133-8.

19. Yin Q, Chen S, Guo W, Huang Y, Huang Y, Zhou R, Fan Q, Liao W. Pronounced genetic differentiation in Fokienia hodginsii revealed by simple sequence repeat markers. Ecol Evol. 2018;8(22):10938-51.

20. Zhang Z, Shang H, Shi Y, Huang L, Li J, Ge Q, Gong J, Liu A, Chen T, Wang D. Construction of a highdensity genetic map by specific locus amplified fragment sequencing (SLAF-seq) and its application to Quantitative Trait Loci (QTL) analysis for boll weight in upland cotton (Gossypium hirsutum.). BMC plant biology. 2016;16(1):79.

21. Zheng X, Tang Y, Ye J, Pan Z, Tan M, Xie Z, Chai L, Xu Q, Fraser PD, Deng X. SLAF-Based Construction of a High-Density Genetic Map and Its Application in QTL Mapping of Carotenoids Content in Citrus Fruit. J Agric Food Chem. 2019;67(3):994-1002.

22. Zhu Z, Li X, Wei Y, Guo S, Sha A. Identification of a novel QTL for panicle length from wild rice (Oryza minuta) by specific locus amplified fragment sequencing and high density genetic mapping. Frontiers in plant science. 2018;9:1492.

23. Li B, Fan S, Yu F, Chen Y, Zhang S, Han F, Yan S, Wang L, Sun J. High-resolution mapping of QTL for fatty acid composition in soybean using specific-locus amplified fragment sequencing. Theor Appl Genet. 2017;130(7):1467-79.

24. Han Y, Zhao X, Liu D, Li Y, Lightfoot DA, Yang Z, Zhao L, Zhou G, Wang Z, Huang L, et al. Domestication footprints anchor genomic regions of agronomic importance in soybeans. New Phytol. 2016;209(2):871-84.

25. Sun X, Liu D, Zhang X, Li W, Liu H, Hong W, Jiang C, Guan N, Ma C, Zeng H, et al. SLAF-seq: an efficient method of large-scale de novo SNP discovery and genotyping using high-throughput sequencing. PLoS One. 2013;8(3):e58700.

26. Jiang B, Liu W, Xie D, Peng Q, He X, Lin Ye, Liang Z. High-density genetic map construction and gene mapping of pericarp color in wax gourd using specific-locus amplified fragment (SLAF) sequencing. BMC Genomics. 2015;16(1):1035.

27. Tao A, Huang L, Wu G, Afshar RK, Qi J, Xu J, Fang P, Lin L, Zhang L, Lin P. High-density genetic map construction and QTLs identification for plant height in white jute (Corchorus capsularis L.) using specific locus amplified fragment (SLAF) sequencing. BMC Genomics. 2017;18(1):355. 
28. He D, Liu Y, Cai M, Pan H, Zhang Q. The first genetic linkage map of crape myrtle (L agerstroemia) based on amplification fragment length polymorphisms and simple sequence repeats markers. Plant Breeding. 2014;133(1):138-44.

29. Zhao Z, Gu H, Sheng X, Yu H, Wang J, Huang L, Wang D. Genome-wide single-nucleotide polymorphisms discovery and high-density genetic map construction in cauliflower using specificlocus amplified fragment sequencing. Frontiers in plant science. 2016;7:334.

30. Luan MBYZ, Zhu JJ, Deng X, Liu CC, Wang XF. Identification, evaluation, and application of the genomic-SSR loci in ramie. Acta Soc Bot Pol. 2016;85(3):3510-21.

31. Su W, Wang L, Lei J, Chai S, Liu Y, Yang Y, Yang X, Jiao C. Genome-wide assessment of population structure and genetic diversity and development of a core germplasm set for sweet potato based on specific length amplified fragment (SLAF) sequencing. PloS one. 2017;12(2):e0172066.

32. Doyle JJ. DJL: A Rapid DNA Isolation Procedure for Small Quantities of Fresh Leaf Tissue. Phytochemical Bulletin. 1987;19:11-5.

33. Aerts J, Sun X, Liu D, Zhang X, Li W, Liu H, Hong W, Jiang C, Guan N, Ma C, et al: SLAF-seq: An Efficient Method of Large-Scale De Novo SNP Discovery and Genotyping Using High-Throughput Sequencing. PLOS ONE 2013, 8(3).

34. Liu F, Zhang Y, Zhang L, Li Z, Fang Q, Gao R, Zhang Z. Systematic comparative analysis of singlenucleotide variant detection methods from single-cell RNA sequencing data. Genome Biol. 2019;20(1):242-56.

35. Yao Z, You FM, N'Diaye A, Knox RE, McCartney C, Hiebert CW, Pozniak C, Xu W. Evaluation of variant calling tools for large plant genome re-sequencing. BMC Bioinformatics. 2020;21(1):360-75.

36. Goedbloed DJ, Megens HJ, Van Hooft P, Herrero-Medrano JM, Lutz W, Alexandri P, Crooijmans RP, Groenen M, Van Wieren SE, Ydenberg RC, et al. Genome-wide single nucleotide polymorphism analysis reveals recent genetic introgression from domestic pigs into Northwest European wild boar populations. Mol Ecol. 2013;22(3):856-66.

37. Sesia M, Katsevich E, Bates S, Candès E, Sabatti C. Multi-resolution localization of causal variants across the genome. Nat Commun. 2020;11(1):1093.

38. Shen C, Jin X, Zhu D, Lin Z. Uncovering SNP and indel variations of tetraploid cottons by SLAF-sEq. BMC Genom. 2017;18(1):247.

39. Guo J, Liu Y, Wang Y, Chen J, Li Y, Huang H, Qiu L, Wang Y. Population structure of the wild soybean (Glycine soja) in China: implications from microsatellite analyses. Ann Bot. 2012;110(4):777-85.

40. Pereira L, Mutesa L, Tindana $P$, Ramsay $M$. African genetic diversity and adaptation inform a precision medicine agenda. Nat Rev Genet. 2021;22(5):284-306.

41. Ropars J, Maufrais C, Diogo D, Marcet-Houben M, Perin A, Sertour N, Mosca K, Permal E, Laval G, Bouchier $\mathrm{C}$, et al. Gene flow contributes to diversification of the major fungal pathogen Candida albicans. Nat Commun. 2018;9(1):2253-62.

42. Ju MM, Feng L, Yang J, Yang YC, Chen XD, Zhao GF. Evaluating Population Genetic Structure and Demographic History of Quercus spinosa (Fagaceae) Based on Specific Length Amplified Fragment 
Sequencing. Front Genet. 2019;10:965.

43. Li B, Tian L, Zhang J, Huang L, Han F, Yan S, Wang L, Zheng H, Sun J. Construction of a high-density genetic map based on large-scale markers developed by specific length amplified fragment sequencing (SLAF-seq) and its application to QTL analysis for isoflavone content in Glycine max. BMC Genomics. 2014;15(1):1086.

44. Liu D, Ma C, Hong W, Huang L, Liu M, Liu H, Zeng H, Deng D, Xin H, Song J. Construction and analysis of high-density linkage map using high-throughput sequencing data. Plos one 2014, 9(6).

45. Wang S, Meyer E, McKay JK, Matz MV. 2b-RAD: a simple and flexible method for genome-wide genotyping. Nature methods. 2012;9(8):808-10.

46. Romiguier J, Gayral P, Ballenghien M, Bernard A, Cahais V, Chenuil A, Chiari Y, Dernat R, Duret L, Faivre $\mathrm{N}$, et al. Comparative population genomics in animals uncovers the determinants of genetic diversity. Nature. 2014;515(7526):261-3.

47. Xu X, Xu R, Zhu B, Yu T, Qu W, Lu L, Xu Q, Qi X, Chen X: A high-density genetic map of cucumber derived from Specific Length Amplified Fragment sequencing (SLAF-seq). Frontiers in plant science 2015, 5:768.

48. Xie D, Dai Z, Yang Z, Sun J, Zhao D, Yang X, Zhang L, Tang Q, Su J. Genome-wide association study identifying candidate genes influencing important agronomic traits of flax (Linum usitatissimum L.) using SLAF-sEq. Frontiers in plant science 2018, 8:2232.

49. Xia C, Chen L-I, Rong T-z, Li R, Xiang Y, Wang P, Liu C-h, Dong X-q, Liu B, Zhao D. Identification of a new maize inflorescence meristem mutant and association analysis using SLAF-seq method. Euphytica. 2015;202(1):35-44.

50. Huang S, Ding J, Deng D, Tang W, Sun H, Liu D, Zhang L, Niu X, Zhang X, Meng M. Draft genome of the kiwifruit Actinidia chinensis. Nature communications. 2013;4(1):1-9.

51. Bai Q, Cai Y, He B, Liu W, Pan Q, Zhang Q. Core set construction and association analysis of Pinus massoniana from Guangdong province in southern China using SLAF-sEq. Sci Rep. 2019;9(1):13157.

52. DeHaan PW, Scheerer PD, Rhew R, Ardren WR. Analyses of genetic variation in populations of Oregon Chub, a threatened floodplain minnow in a highly altered environment. Trans Am Fish Soc. 2012;141(2):533-49.

53. Zhang S, Li B, Chen Y, Shaibu AS, Zheng H, Sun J. Molecular-Assisted Distinctness and Uniformity Testing Using SLAF-Sequencing Approach in Soybean. Genes. 2020;11(2):175.

54. Ding WN, Ree RH, Spicer RA, Xing YW. Ancient orogenic and monsoon-driven assembly of the world's richest temperate alpine flora. Science. 2020;369(6503):578-81.

\section{Figures}




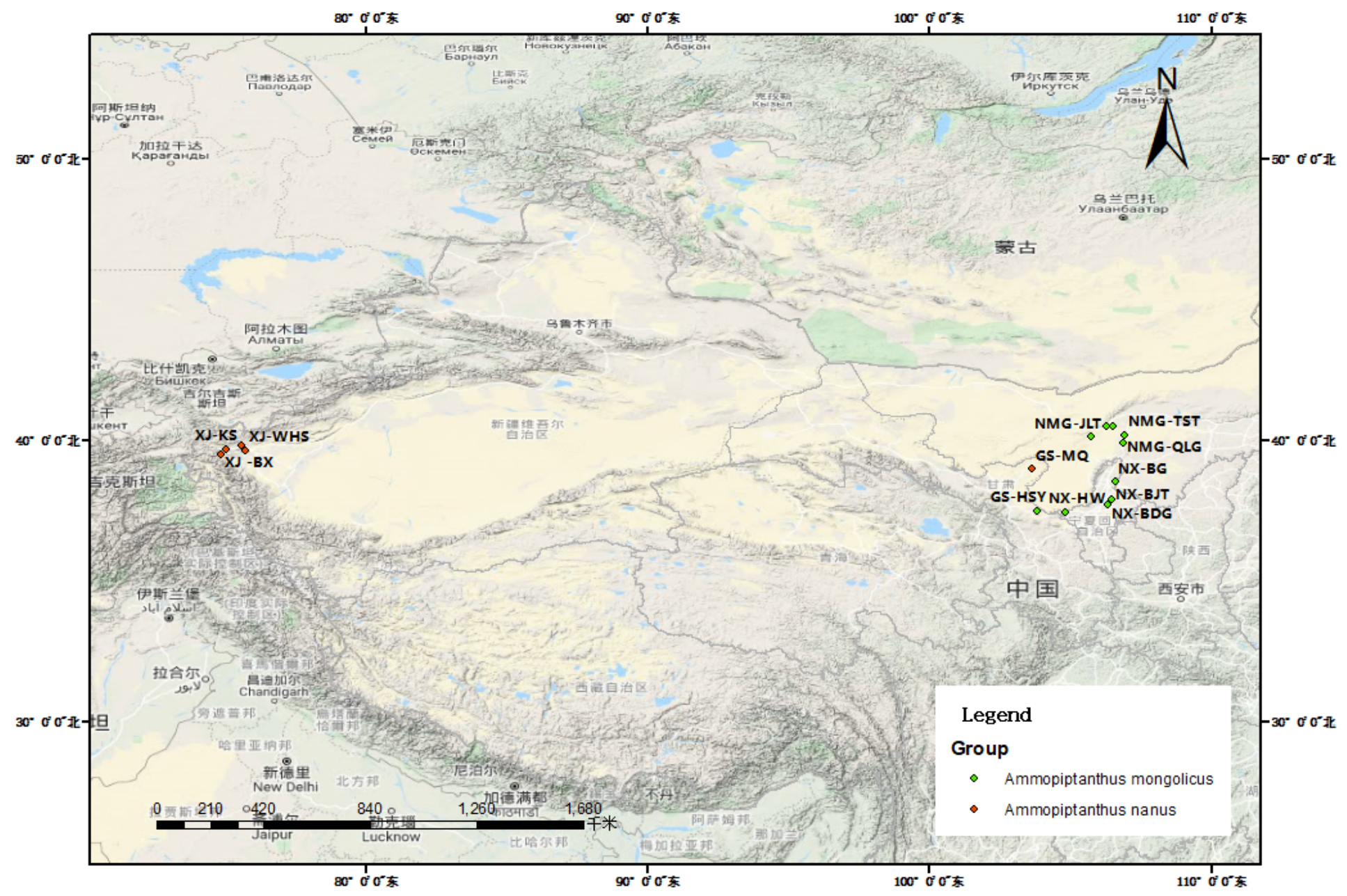

\section{Figure 1}

Map showing locations of the populations of Ammopiptanthus. 


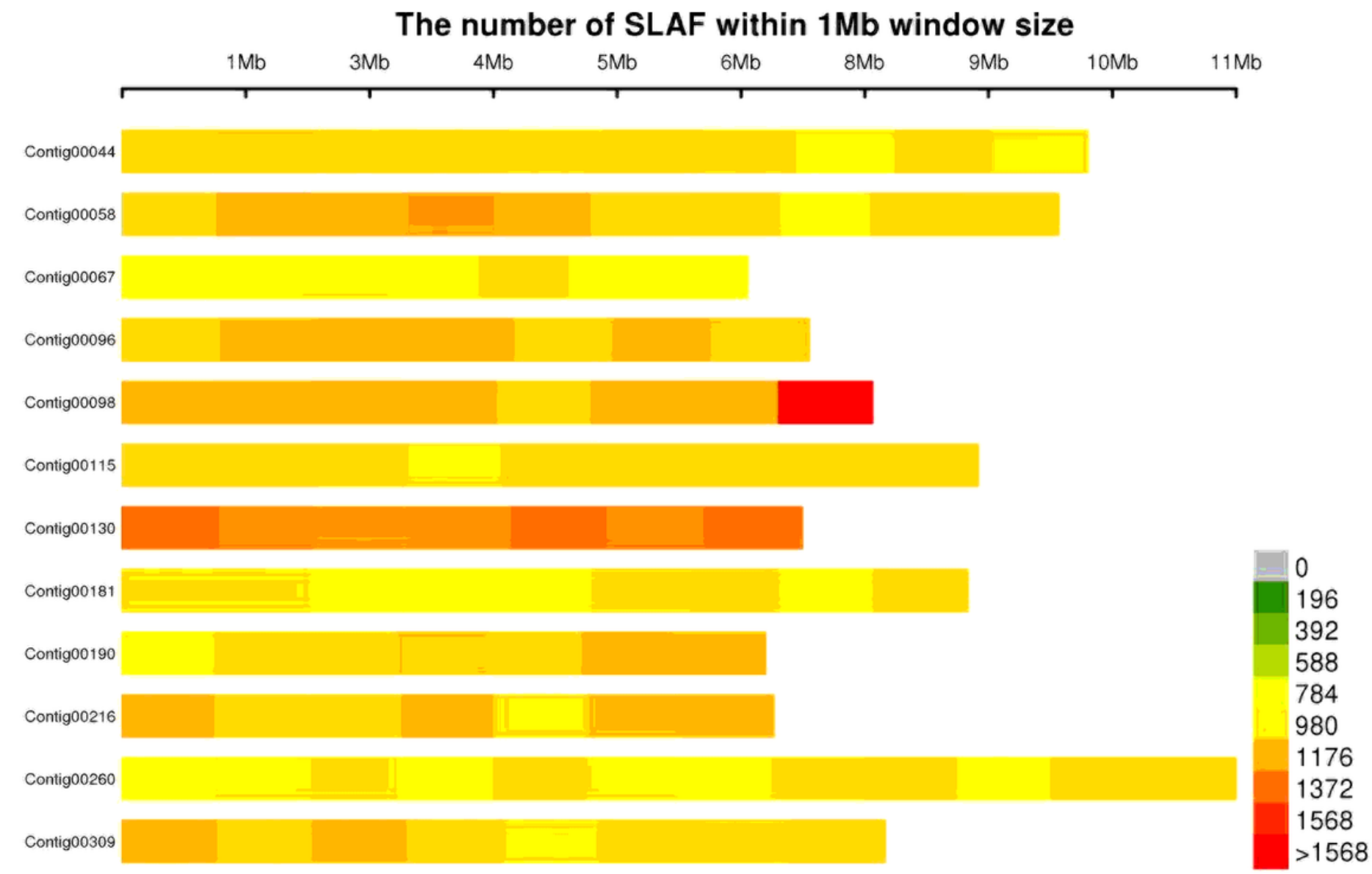

Figure 2

Distribution of SLAF tags on chromosomes of 111 Ammopiptanthus species. 


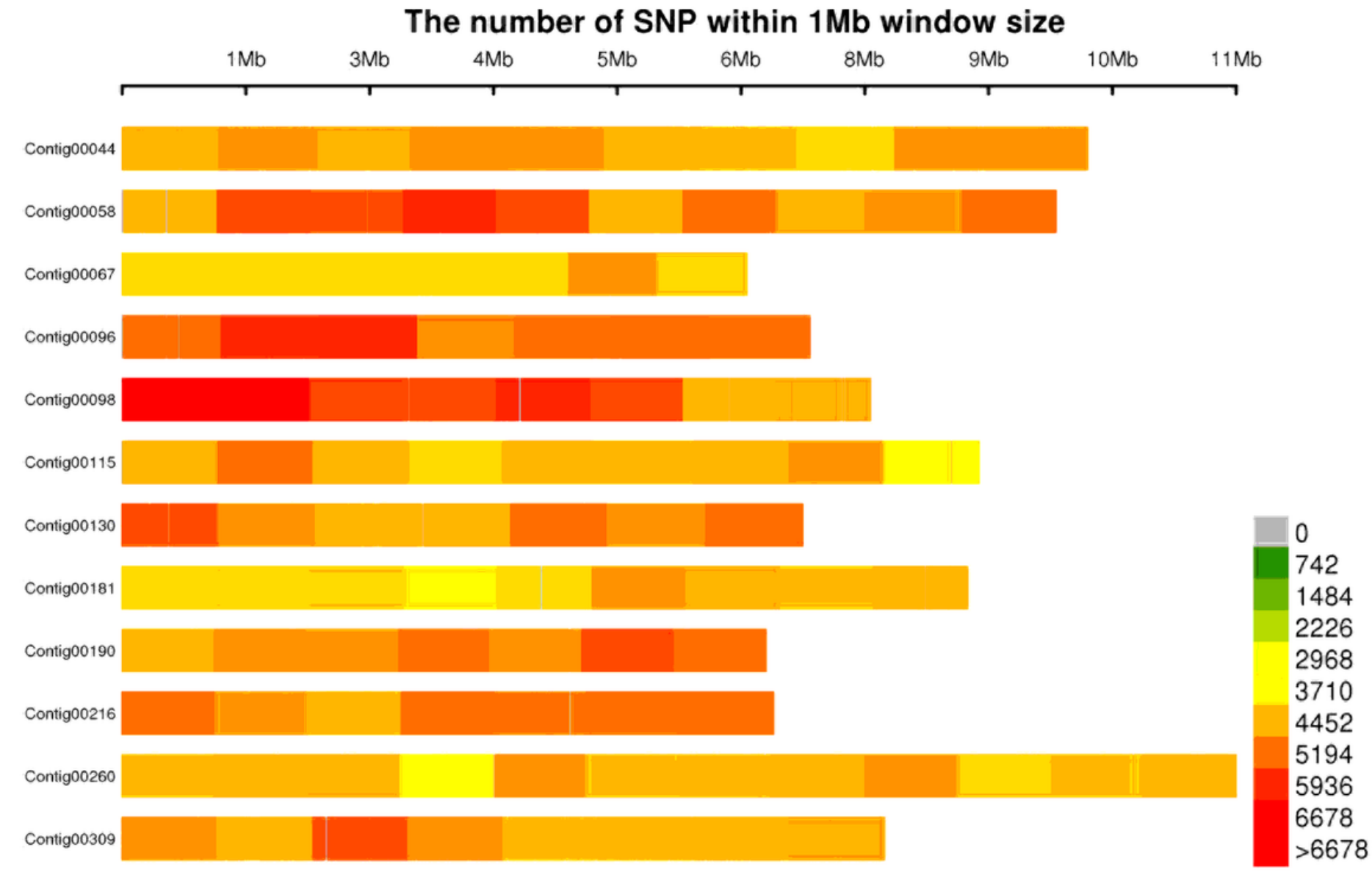

\section{Figure 3}

Distribution of SNPs on 111 Ammopiptanthus chromosomes. Thex-axis represents the physical length of the chromosome. 


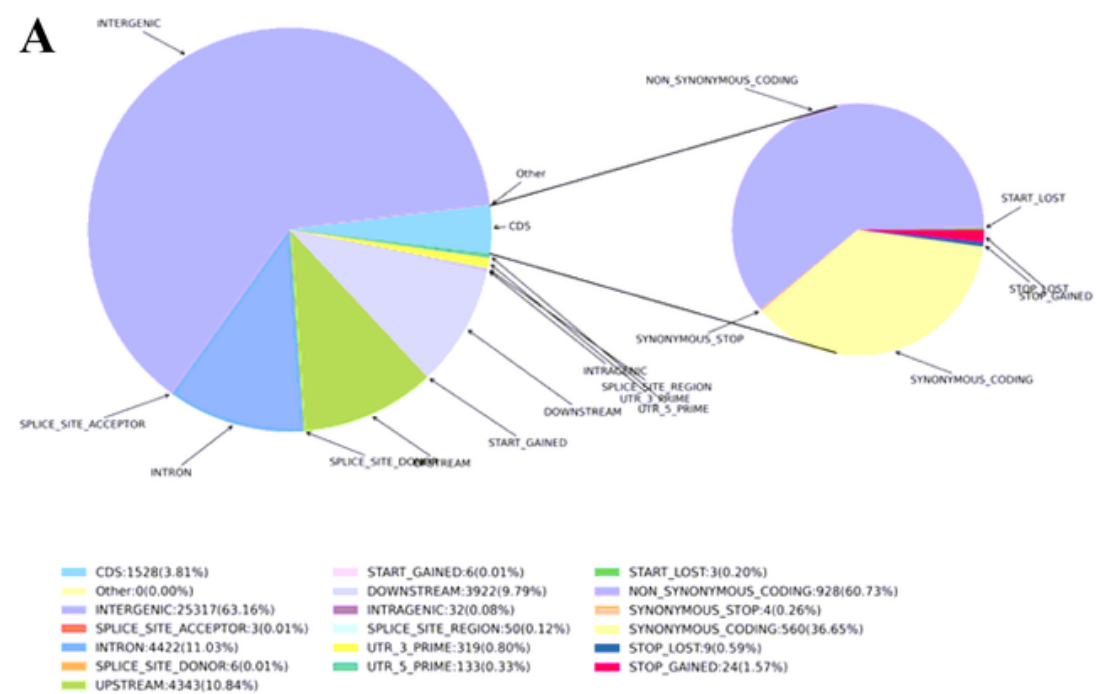

B Indel Length Distribution

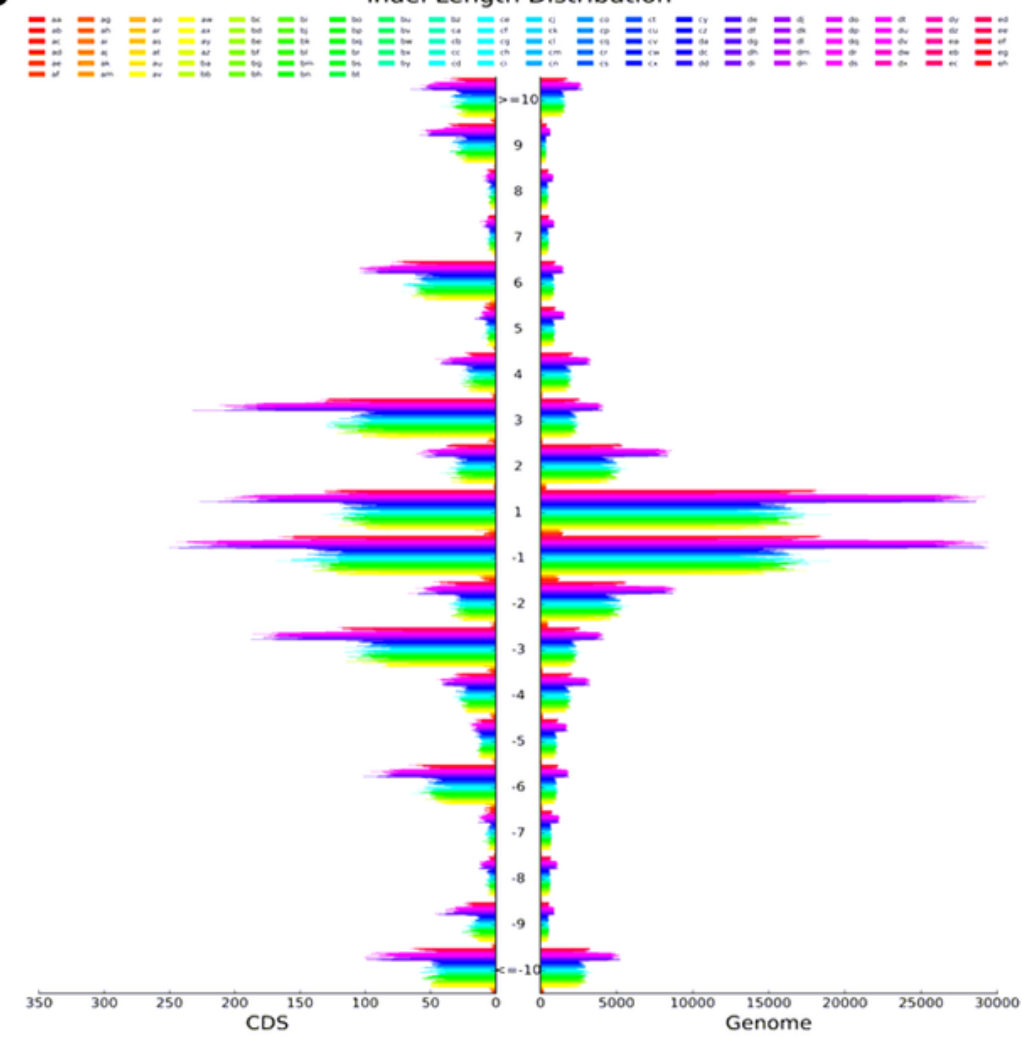

\section{Figure 4}

Annotation of InDels in 111 Ammopiptanthus species. (A) Distribution of InDels in different intergenic and genic regions among 111 Ammopiptanthus population species. In CDS region, the number of synonymous and non-synonymous InDels detected has also shown among the Ammopiptanthus species species. (B) InDels length distribution in different genomic regions for the 111 Ammopiptanthus species. 


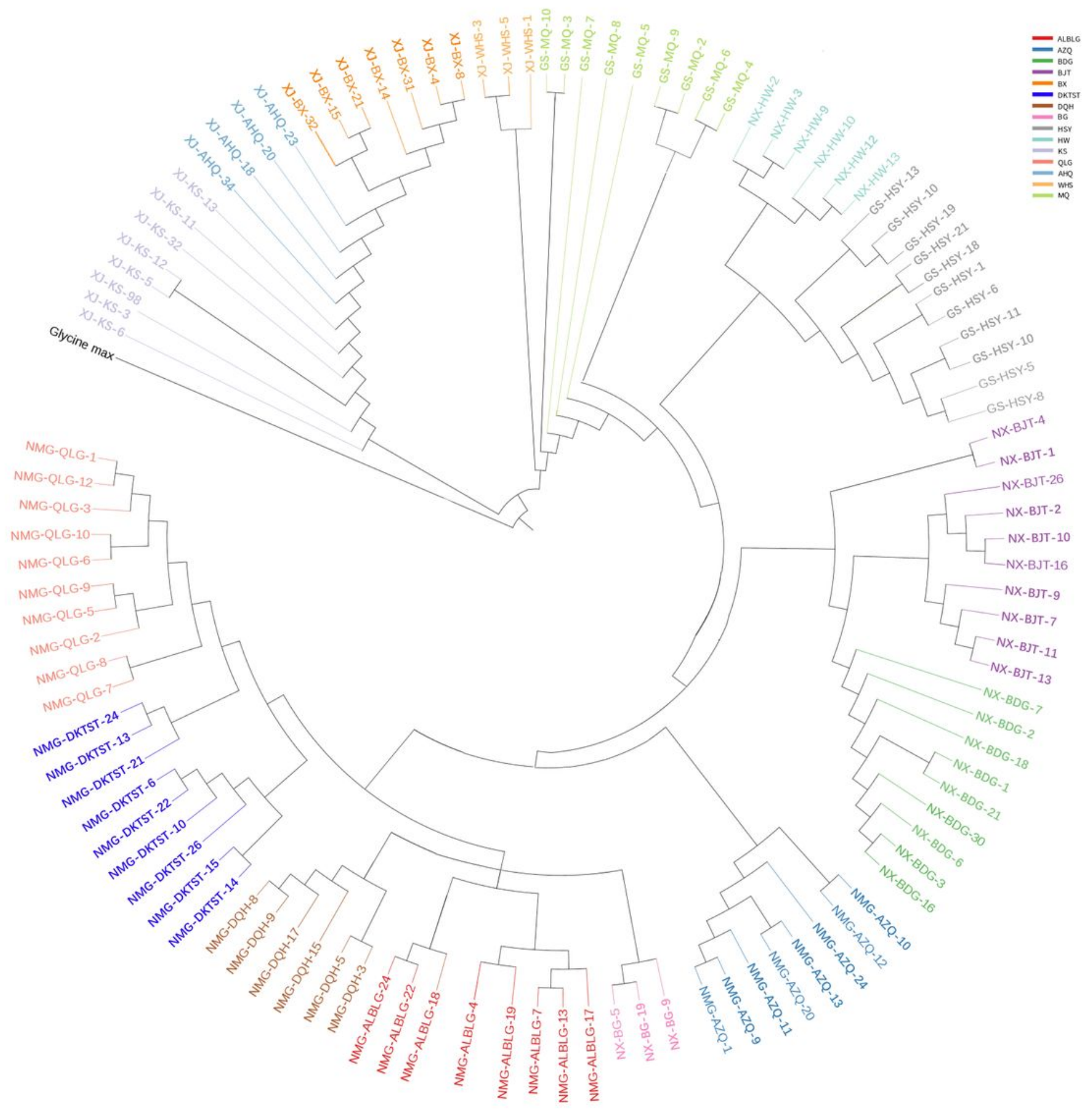

Figure 5

Phylogenetic tree of the 111 individuals based on the analysis of 457,888 single nucleotide polymorphisms (SNPs). 

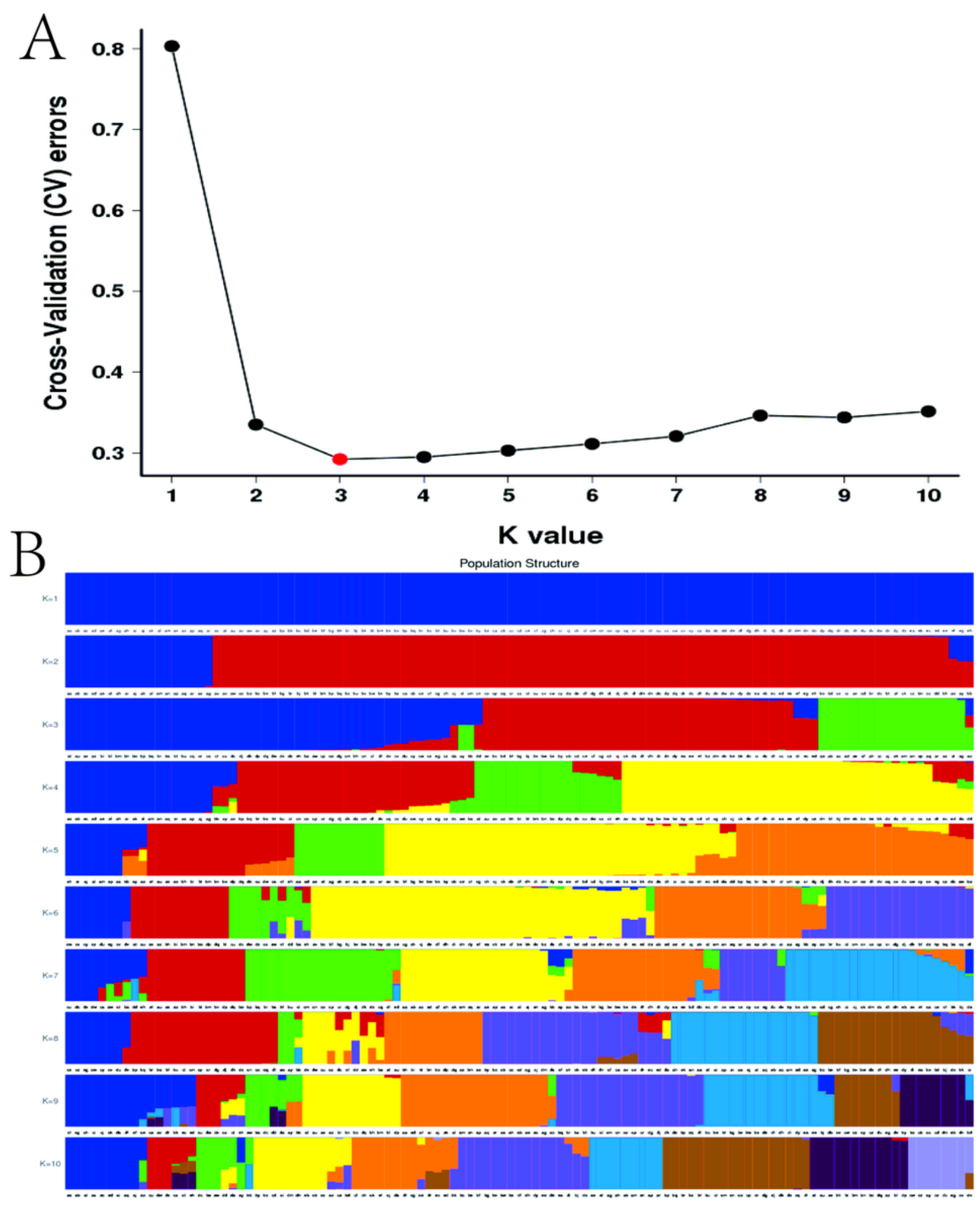

\section{Figure 6}

Population structure analysis of the Ammopiptanthus accessions (111 genotypes) by the Admixture program using genome-wide SNP markers. (A) The estimated cross-validation errors for different grouping results (K value). (B) Groups identified in the structure analysis by a predefined K (group number) from 1 to 10 . 


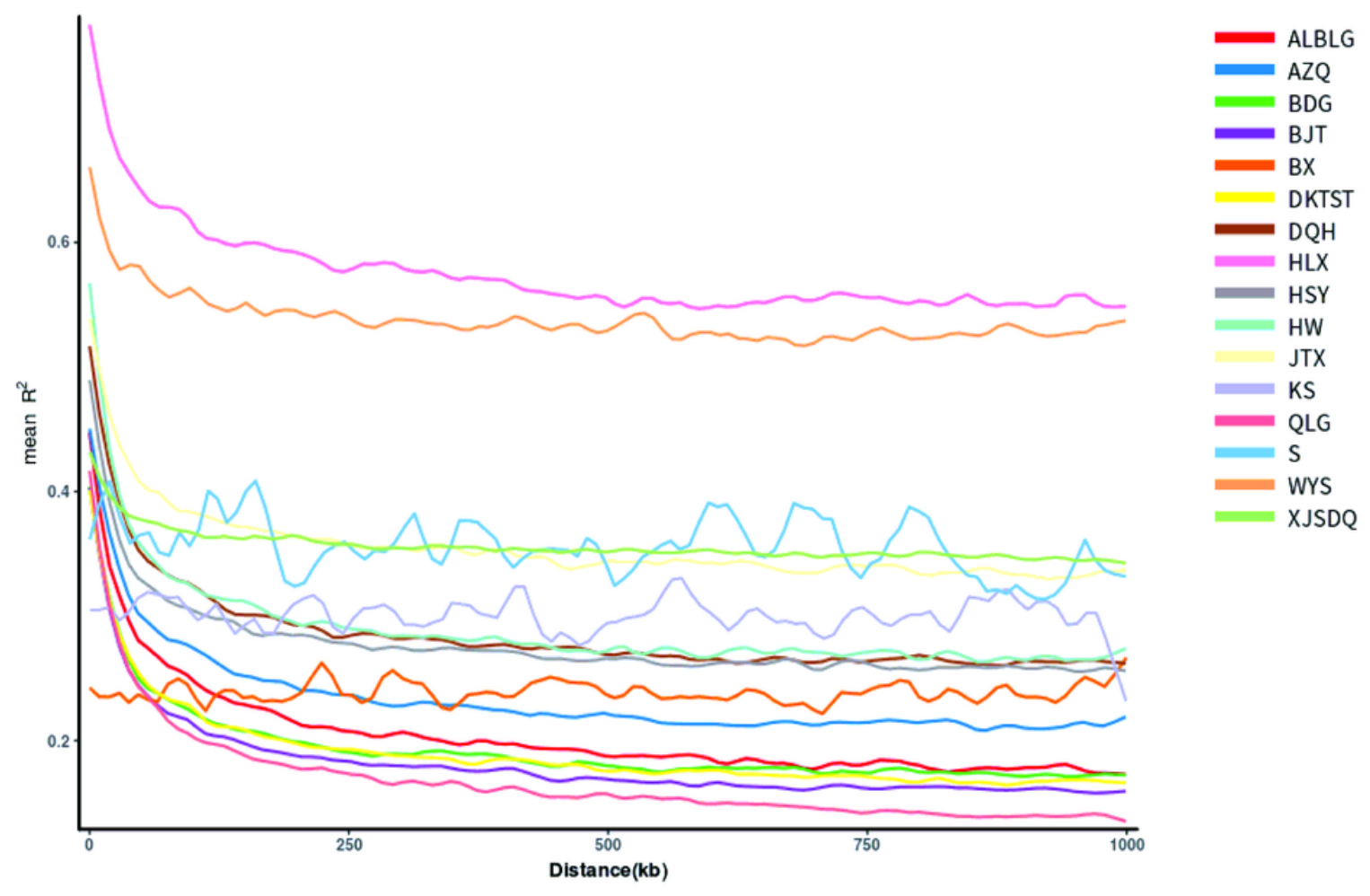

Figure 7

Linkage Disequilibrium Analysis. 


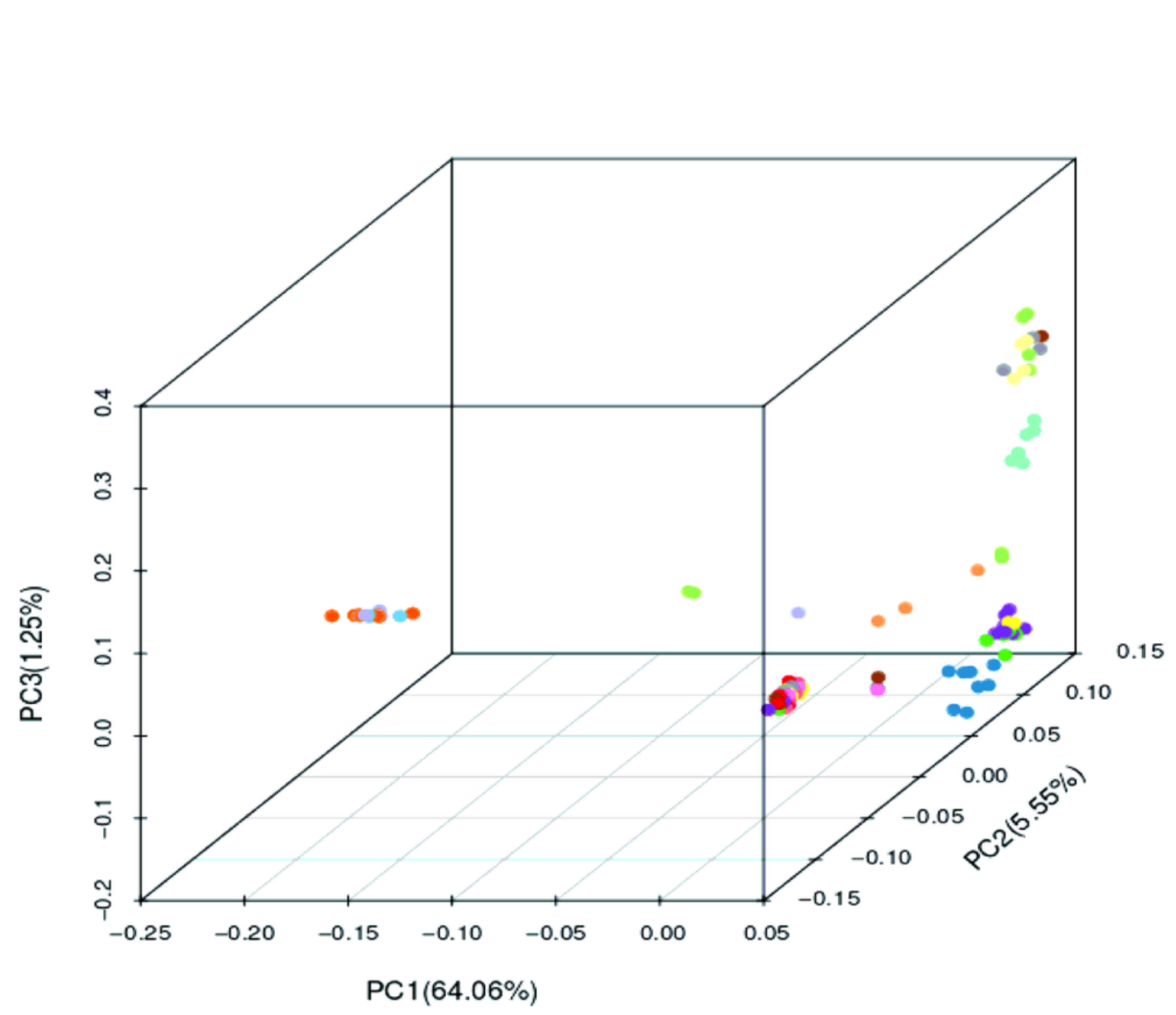

- ALBLG

- $A Z Q$

- BDG

- BJT

- BX

DKTST

- DQH

- HLX

- HSY

- HW JTX

- KS

- QLG

- S

- WYS

- XJSDQ

\section{Figure 8}

The principal component analysis (PCA) clustering among Ammopiptanthus samples.

\section{Supplementary Files}

This is a list of supplementary files associated with this preprint. Click to download.

- Supplementary.doc 